Disponível em:

http://editora.unoesc.edu.br/index.php/race

Race, Joaçaba, v. 15, n. 2, p. 475-504, maio/ago. 2016

\title{
ATORES BUROCRÁTICOS E SUA ATUAÇÃO POLÍTICA NO INTERIOR DA GESTÃO GOVERNAMENTAL
}

Bureaucratic actors and their politic actions inside the governmental management

Eduardo José Grin

E-mail: eduardo.grin@fgv.br

Mestre em Ciência Política pela Universidade de São Paulo; Doutorando em Administração Pública e Governo pela Fundação Getúlio Vargas de São Paulo; Professor-tutor da Escola de Economia de São Paulo.

Endereço para contato: Rua Itapeva, 474, Bela Vista, 01332-902, São Paulo, São

Paulo, Brasil

Artigo recebido em 10 de junho de 2015. Aceito em 13 de abril de 2016. 


\section{Resumo}

No artigo se aborda a relação entre a burocracia e a política interorganizacional, especialmente sob a ótica da coordenação intragovernamental. O objetivo geral foi analisar criticamente autores das áreas de Administração Pública, Sociologia das Organizações e Ciência Política à luz do problema como proposto e da pergunta da pesquisa como formulada. Em termos específicos, buscou-se discutir o tema sob dois enfoques complementares: a dinâmica interorganizacional do poder público enfatizando os desafios para se obter integração intragovernamental em face dos obstáculos institucionais e políticos que existem, e o papel e ação das burocracias públicas como atores políticos e os efeitos gerados nos domínios de políticas públicas e na gestão interna do aparato estatal. A metodologia utilizada foi a análise qualitativa de conteúdo, sendo as bibliografias de Administração Pública, Sociologia das Organizações e Ciência Política consideradas o corpus empírico. Conclui-se que os atores burocráticos são peças vitais para se compreender a dinâmica intragovernamental e as políticas que resultam desse processo como um jogo de poder. Se as instituições não podem ser consideradas meros reflexos do ambiente externo, pois também influenciam a vida social, os conflitos interburocráticos podem ser uma variável relevante na análise dessa questão.

Palavras-chave: Atores burocráticos. Política interorganizacional. Coordenação intragovernamental.

Abstract

The article discusses the relationship between bureaucracy and interorganizational politics, especially from the perspective of intra-governmental coordination. The overall goal was to critically analyze authors from the fields of Public Administration, Organizational Sociology and Political Science in the light of the problem as proposed and the research question as formulated. Specifically, it is discussed the topic from two complementary approaches: the interorganizational dynamics of the public power emphasizing the challenges to achieve intragovernmental integration in the face of the institutional and political obstacles that exist; and the role and action of public bureaucracies as political actors and the effects generated in the fields of public policy and the internal management of the state apparatus. The methodology was qualitative content analysis, and the bibliography of Public Administration, Organizational Sociology and Political Science was considered the empirical corpus. It is concluded that the bureaucratic actors are vital pieces to understand the intra-government dynamic and the policies that result from this process as a power game. If institutions cannot be considered mere reflections of the external environment, because they also influence the social life, interbureaucratic conflicts may be a relevant variable in the analysis of this issue.

Keywords: Bureaucratic actors. Interorganizational politics. Intra-governmental coordination. 


\section{INTRODUÇÃO}

Neste ensaio se aborda a relação entre a burocracia e a política interorganizacional, especialmente sob a ótica da coordenação intragovernamental. Essa é uma questão importante para a Administração Pública, pois a forma como seu aparato organizacional e institucional se estrutura pode gerar dificuldades de coordenar ações entre as suas burocracias. No artigo discutem-se alguns aspectos apresentados nas literaturas de Ciência Política, Sociologia das Organizações e Administração Pública. Entende-se que essa discussão pode ampliar o debate clássico que trata das tensões entre políticos, burocracias e cidadãos, mas que não inclui a vida interorganizacional e as disputas no interior do Estado. Se as instituições não podem ser compreendidas como meros reflexos do ambiente externo, pois também influenciam a vida social, os conflitos interburocráticos podem ser uma variável relevante na análise dessa questão. E se instituições podem ter algum poder explicativo sobre os resultados da ação governamental, a forma como se estruturam as relações entre os atores burocráticos é um aspecto relevante para se qualificar a compreensão do jogo político interno às organizações públicas.

O estudo da "política interorganizacional” (PETERS, 1998; O’TOOLE Junior, 2010) ou "integração governamental” (POLLIT, 2003) não é novo. A questão pode ser também abordada com o apoio de tradições teóricas como o incrementalismo (LINDBLOM, 1959). Para Lindblom (1980), se as barganhas e ajustes adaptativos servem para ilustrar a "política burocrática", os arranjos resultantes podem refletir possibilidades contingentes de acordos antes de uma distribuição mais eficiente de atribuições. Pela lógica do garbage can (COHEN; MARCH; OLSEN, 1972), como as burocracias possuem "soluções em busca de problemas", pode-se intensificar a disputa interorganizacional e a competição entre os atores organizacionais. Desse ponto de vista, as disputas interburocráticas podem ocorrer menos motivadas por premissas de racionalidade entre meios e fins e mais pelos interesses políticos em ampliar domínios institucionais. A concepção da racionalidade limitada também é uma referência para se analisar a política interorganizacional. Se a compreensão da realidade é incompleta para os atores, o efeito pode ser transformar a informação de recurso escasso em instrumento de barganha, considerando-se que burocracias buscam preservar seus domínios.

Pela ótica da Ciência Política, especialmente segundo o pluralismo, também é possível uma aproximação teórica com a questão. Na visão de Dahl (1989), as ações dos atores políticos denotam quem detém poder, e os atores burocráticos, ao externalizarem decisões, mostram quem possui tais recursos políticos. Ainda no pluralismo, 
para Bachrach e Baratz (1962), o poder também é a capacidade de os atores evitarem temas: burocracias podem agir para afastar questões que pouco lhes interessam no debate intragovernamental. Isso configuraria um contexto de "pluralismo institucional”: burocracias manejam recursos desiguais de poder organizacional e disputam espaços no interior do aparelho de Estado. Tal visão somente faz realçar o caráter da administração pela tônica da política interorganizacional. Existem vários termos para se analisar essa questão, o que pode indicar a dificuldade de um entendimento mais consensual entre os estudiosos. Palavras como coerência, consistência, colaboração, cooperação, coordenação e integração, nos termos de Stead (2006), expressam a mesma questão.

Considerando-se essa contextualização do problema teórico e suas implicações empíricas, vê-se suas conexões com o jogo político que influi na dinâmica das ações e vínculos internos ao aparelho estatal. Sob essa ótica, a coordenação intragovernamental é um desafio político, pois as burocracias podem ser atores com suas preferências e interesses. Esses atores, ao realizarem escolhas e definirem alternativas e cursos de ação no interior do aparato estatal, podem ser movidos mais por valores e interesses do que por critérios técnicos ou racionalidade administrativa. Assim, a questão central nesse artigo é avaliar em que medida a política, com suas dimensões de conflito, barganha, negociação, e o jogo do poder podem ser recursos teóricos analíticos para se compreender a política interorganizacional na vida intragovernamental. Busca-se discutir o tema sob dois enfoques complementares a dinâmica interorganizacional do poder público enfatizando os desafios para se obter integração intragovernamental em face dos obstáculos institucionais e políticos que existem, e o papel e ação das burocracias públicas como atores políticos e os efeitos gerados nos domínios de políticas públicas e na gestão interna do aparato estatal.

Parte-se da premissa que esse é um tópico relevante para a análise da gestão governamental, pois gera impactos nas agendas decisórias. A Ciência Política, mais que a área de Administração Pública, ao discutir a implementação das políticas públicas, traz à tona o papel das burocracias. Contudo, o jogo político interorganizacional no interior dos governos não se resume a isso, a despeito da importância que as disputas nas arenas de políticas públicas possam ter nos termos de Lowi (1964). Existe um espaço analítico que merece uma discussão teórica mais dedicada dos conflitos intraburocráticos no interior do jogo político governamental. Nesse sentido, neste trabalho busca-se contribuir para esse debate.

Para tratar desse tema, o artigo foi dividido em dois eixos: discutir a política organizacional no interior dos governos e analisar a ação das burocracias como atores 
nesse processo. Sendo o artigo um esforço analítico baseado nas literaturas de Administração Pública, Sociologia das Organizações e Ciência Política sobre a política interorganizacional, não se apresenta uma fundamentação teórica específica. Com o texto visa-se discutir criticamente os aportes teóricos das três disciplinas referenciadas, mas, ainda assim, segundo o roteiro metodológico apresentado a seguir.

\section{METODOLOGIA E FUNDAMENTAÇÃO TEÓRICA}

A questão central do ensaio é trazer autores dos três campos teóricos apresentados para se verificar como abordam o tema da política interorganizacional, e como esse processo incide na dinâmica intragovernamental. O problema a ser discutido é se as burocracias públicas podem ser consideradas atores políticos no interior da política interorganizacional. Conforme Gil (2010), definir um problema também é central em uma pesquisa bibliográfica e se constitui o principal recurso metodológico para gerar foco analítico. Mas, como este trabalho é uma pesquisa preliminar e um estudo exploratório (GIL, 2010), espera-se que as conclusões indiquem outras possibilidades para futuras investigações.

Com a pesquisa bibliográfica realizada se analisou a literatura interdisciplinar em Sociologia das Organizações, Administração Pública e Ciência Política acerca do tema. Ainda, conforme Gil (2010), esse procedimento, mesmo não sendo extensivo, tem a vantagem de permitir a síntese de uma ampla gama de autores e abordagens teóricas relacionadas ao problema posto em discussão. Em termos metodológicos, a revisão bibliográfica é conforme McMenamin (2006, p. 133), “[...] também um processo de leitura, de pensar sobre e escrever sobre a literatura acadêmica.” Em outros termos, para esse autor, uma questão essencial é realizar uma seleção de textos, chamada de imaginativa, que possa, durante e ao final da análise realizada, propor contribuições teóricas relevantes. Para Knopf (2006), isso significa realizar uma seleção de literatura não tradicional (visões já conhecidas) e orientada por um foco claro sobre os estudos que são mais relevantes e úteis para a questão de interesse.

No que serve a esse trabalho, essa conduta metodológica foi considerada na proposição do problema, visando escapar de abordagens mais clássicas e já conhecidas sobre a burocracia. Ao mesmo tempo, é proposto um enfoque mais amplo e interdisciplinar para inserir os atores burocráticos na política interorganizacional como orientação para selecionar a literatura analisada. McMenamin (2006) chama essa leitura de instrumental, pois é focada exclusivamente em autores que tratam do problema da pesquisa e podem gerar insights relevantes que ajudem o autor a se situar 
em relação ao campo de conhecimento. Por essa mesma razão, para McMenamin (2006, p. 135) e Knopf (2006), rever uma literatura dirigida por um problema, ainda que teórico, como é o caso de pesquisas bibliográficas, deve buscar, como foi o caso neste ensaio:

a) não ser apenas uma sucessão de revisões de livros, pois deve haver um argumento que confere foco analítico alinhado em torno de uma visão geral;

b) observar uma ordem intelectual sobre os materiais ao agrupar autores em campos mais “largos” de diferentes tradições teóricas, o que ajuda a localizar linhas de discussão similares;

c) não tratar dos trabalhos individuais apenas com um sumário, pois os mesmos devem ser submetidos à análise crítica à luz do problema da pesquisa;

d) discutir a literatura revisada visando propor novas questões e, sendo possível, oferecer novas respostas teóricas;

e) oferecer questões relativas ao conhecimento do tema como contribuições ou valor adicionado para novos estudos que podem ser pontos de partida submetidos ao escrutínio público por outros pesquisadores;

f) enfatizar pontos de convergência e divergência na literatura analisada, além de indicar problemas e gaps que requerem pesquisas adicionais.

Visando atender a esses requisitos metodológicos de uma revisão de literatura, neste ensaio utilizou-se a técnica da análise de conteúdo com a qual, segundo Bardin (2008), busca-se produzir inferências e conhecimento relativo às suas condições de produção. Gerar inferências é a questão principal, visando deduzir, de maneira lógica, conhecimentos a partir, entre outras fontes, das bases documentais existentes que, nesse caso, constituem o que o autor chama de corpus empírico. As palavras-chave buscadas na análise do material foram burocracia (atores burocráticos), política interorganizacional e integração (interação), para em torno delas organizar a leitura e a revisão crítica da literatura. Neste ensaio, a análise empírica se limita aos autores de Administração Pública, Sociologia das Organizações e Ciência Política. Ademais, com base nessa análise, indicam-se limites e possibilidades teóricas que podem ser seguidas ao se criticar a visão dos autores. Para tanto, os autores foram analisados da seguinte forma: 
a) cotejados com a discussão teórica sobre o tema da política interorganizacional e seus vínculos com a dinâmica da coordenação intragovernamental e o jogo de poder intraburocrático;

b) analisados comparativamente buscando-se encontrar semelhanças e diferenças de abordagem em seus propósitos. Essa é uma questão importante, pois o campo teórico da discussão é multidisciplinar diante de suas dimensões administrativas, organizacionais, sociológicas e políticas;

c) contextualizados para se buscar ampliar seus pontos de vista teóricos como um recurso para indicar formas de aprofundar, criticar ou revisar suas abordagens.

\section{POLÍTICA INTERORGANIZACIONAL E INTEGRAÇÃO INTRAGOVERNAMENTAL}

Segundo Peters (1998), a cooperação intragovernamental emerge das dificuldades dos governos em um contexto em que:

a) ampliam sua intervenção na vida social com programas que acabam se influenciando mutuamente;

b) novas formas organizacionais, como agências descentralizadas, desagregam estruturas e demandam mais coordenação;

c) problemas fiscais requerem mais coordenação para reduzir redundâncias e eliminar custos;

d) novas formas de governança pública reduzem a possibilidade de se considerarem usuários e servidores de uma organização sem referência a outros segmentos;

e) a transversalidade de políticas se tornou uma realidade para os governos.

Em linha com essa avaliação, para O’Toole Junior (2010, p. 232):

[...] a simples expansão das pautas governamentais impulsiona conflitos jurisdicionais, sobreposições e possíveis desavenças. À medida que o "espaço político" fica cada vez mais repleto de programas e iniciativas públicas, torna-se ainda mais difícil operar sem que um esforço em particular esbarre em programas relacionados e em influências gerenciadas alhures pelo governo - geralmente outros departamentos do mesmo governo. Em tais circunstâncias faz sentido tentar ligar as operações de alguma 
maneira ou fornecer algum tipo de infraestrutura social de consulta mútua e compartilhamento de informações.

Diante desse cenário, para Peters (1998), os governos devem evitar redundâncias, incoerências e lacunas residuais nas suas ações ${ }^{1}$. O objetivo deveria ser “[...] alinhar estruturas e atividades para promover ou facilitar a probabilidade de alcançar objetivos horizontais [e] reduzir sobreposições.” (BAKVIS; JUILLET, 2004, p. 17). Assim se evitaria a “coordenação negativa” ou o que Martins (2005, p. 10) caracteriza como “coordenação não-negociada”. A resposta, segundo Bakvis e Juillet (2004), seria definir "mecanismos colaborativos” como coordenação e gestão de atividades entre duas ou mais unidades organizacionais, de modo que as unidades não exerçam controle hierárquico sobre as outras, visando gerar resultados que não podem ser alcançados isoladamente por cada uma delas. Mas, para Stead (2006, p. 6), é difícil identificar incentivos ao trabalho intersetorial e objetivos multisetoriais de governo, o que a torna uma política de baixa prioridade, ademais, pouco efetiva.

A posição mencionada pode ser contrastada com aquela formulada por Lindblom (1980) ao enfatizar que a organização dos governos é um resultado da interação entre unidades internas e seus interesses específicos. Essa relação funciona como método de controle mútuo entre os níveis organizacionais, atenua conflitos, soluciona problemas e influencia a formulação de políticas ao gerar efeitos sobre a estrutura interna de poder. Os processos de análise (técnica e administrativa) não podem ser separados da política (processo de decisão). Essa aproximação ajuda a caracterizar como os governos organizam sua interação política interna e os instrumentos de controle e decisão.

Portanto, na definição de políticas públicas, as unidades internas e as pessoas interagem exercendo influência, controle ou poder umas sobre as outras. A persuasão, o intercâmbio e a autoridade são os métodos mais comuns no jogo de poder intragovernamental. Por isso que um "sistema de governo é um sistema de autoridade" definido por mecanismos de comando e ajuste mútuo entre organizações que negociam entre si, visando atender seus interesses por meio de mediação, confronto ou cooperação. Para Lindblom (1980), os incentivos à política interorganizacional decorrem de sua natureza intrínseca, pois compreende que o "pluralismo organizacional” estimula a barganha e a negociação interburocrática que tende ao equilíbrio em um jogo de ganha-ganha. Os atores organizacionais, caso concluam que pequenos ganhos incrementais podem ser mais seguros que as apostas de jogos de soma zero, aceitam acordos intraburocráticos, mesmo que sejam subótimos em relação às suas preferências. 
Segundo Lindblom (1980), nessa interação, os órgãos podem colidir entre si e descobrir responsabilidades sobrepostas que gerem cooperação mútua, controle ou obstrução recíproca que produzem efeitos políticos e administrativos para os governos. Essa interação entre os órgãos gera, portanto, atos de decisão política e estrutura um processo decisório predominantemente nas mãos da burocracia. Nesse modelo, chamado de política burocrática, os policy makers são constrangidos pela ação dos atores burocráticos. Opinião semelhante é expressa por Mintzberg (1998) ao dizer que as atividades de governo são interconectadas, e a relação entre políticos e administradores não mais reproduz a separação entre concepção e implementação no tratamento das políticas públicas. Jamil (1998) também argumenta que a burocracia é parte do sistema político já que, além de seu conhecimento técnico, ajuda a formular políticas, pois seus interesses influem sobremaneira nesse processo. Por esse motivo, temas de administração pública são, ao mesmo tempo, políticos e de cultura administrativa e não apenas organizacionais.

Tais dificuldades podem se apresentar quando problemas de negociação, barganha e conflito envolvem interesses dos atores organizacionais nas políticas públicas. Nessas situações, é importante conhecer os “diferentes interesses” da burocracia, identificar suas preferências de políticas e como defendem seus espaços no jogo de poder no interior da administração pública. Uma forma para se analisar esse tipo de cenário é fazer uso do que O’Toole (2010) chama de bandwagon effects ("efeitos de arraste”): premissas comuns de políticas criadas desde o início influem em trajetórias mais promissoras de interação organizacional. Contudo, segundo March e Olsen (2008), é um equívoco pressupor que as organizações compartilham objetivos ou, mesmo diante da existência destes, que a gestão dos conflitos embasaria per se acordos mútuos.

A forma como as organizações públicas decidem sobre suas políticas, geralmente, é cercada mais de incertezas sobre o desenho das ações, de mecanismos claros de execução e de cenários mais alinhados de resultados possíveis. E esses efeitos não apenas podem ser decorrentes de incapacidade técnica ou ausências de opções gerenciais, mas, sobretudo, do limite possível dos acordos políticos intraburocráticos que possuem sua própria dinâmica. Mesmo em contextos em que a formulação de ações consiga ser mais consensual, os atores burocráticos podem atuar na etapa de implementação das políticas, visando a preservar seus interesses organizacionais, opções técnicas de execução ou mesmo orçamentários.

Portanto, mesmo a integração em um nível da política interorganizacional não garante sucesso em outra fase. E esse resultado pode ocorrer se a dinâmica parti- 
cular das instituições e suas burocracias for proeminente no jogo de poder interorganizacional. Isso porque mesmo diante de objetivos organizacionais coincidentes podem existir desafios políticos à interação que gerem problemas de coerência e unidade em torno de uma mesma agenda. Assim, em vez de se gerar complementaridade entre políticas, amplifica-se o dilema da duplicidade de iniciativas (MARTINS, 2005). Também pode ser que as várias burocracias compartilhem finalidades de políticas cuja relevância seja distinta ou mesmo secundária para todas elas, visando preservar espaços de autonomia naquilo que é mais estratégico. Portanto, segundo Ariznabarreta (2001, p. 11), importa identificar se:

[...] a interdependencia como factor desencadenante de la coordinación está mediatizada por su percepción. Con ello queremos decir que hasta que dos unidades no se reconozcan como mutuamente dependientes será difícil que acepten espontáneamente la necesidad de coordinación. Este déficit de percepción es frecuente en organizaciones y unidades cuya introspección y aislamiento les hace miopes a visualizar la coincidencia con otras en un entorno de trabajo. Reforzar la capacidad de comprensión del entorno y el reconocimiento de los actores intervinientes es, por lo tanto, un primer paso para fundar capacidades de coordinación.

Afora os estímulos institucionais, o intercâmbio interorganizacional envolve criar uma direção política comum e desenvolver uma cultura de confiança e a solução conjunta de problemas. Nesse sentido, poderia transitar-se de um modelo de comando burocrático para outro baseado na negociação interorganizacional (BOGASON, 1998). Esses arranjos demandam construir e manter compromissos entre os participantes, para o que as regras do jogo colaborativo, e sua arbitragem, devem ser negociadas. Um mecanismo para avançar nessa direção podem ser acordos formais que coordenem esforços de parceria interorganizacional e definam as responsabilidades de cada parte (POLLIT, 2003). Para Stead (2006, p. 2), essa coordenação política envolve: cooperação de políticas que implicam diálogo e informação; coordenação, coerência e consistência de políticas para evitar conflitos e atingir objetivos consensuais, e integração de políticas, que inclui as duas modalidades anteriores e busca criar sinergias e situações de ganha-ganha entre políticas. Essa é uma sequência de “ajustamentos mútuos” que visam obter maior interdependência, compatibilidade e interação entre as organizações e suas burocracias. Assim, o gerenciamento horizontal deveria incluir redução da duplicação, consistência de políticas em diferentes setores/ níveis de decisão verticais e melhorara da implantação de políticas transversais. Isso 
caracterizaria um marco compartilhado de atuação para fortalecer o intercâmbio organizacional (ECHEBARRIA, 2001).

Mas se as organizações que atuam em um campo de políticas concorrem em termos de objetivos e clientelas, e se possuem os recursos necessários para tais ações, podem existir poucos estímulos à cooperação. Nesse ponto, Pollit (2003, p. 42) registra o problema da "fragmentação de formas organizacionais", decorrente de políticas individuais dos órgãos que podem se sobrepor à busca de cooperação e ocasionar ações descoordenadas. Nessa linha, Lowndes e Skelcher (1998, p. 317) argumentam que relacionamentos cooperativos têm mais chance de sucesso se encontram soluções de equilíbrio para problemas comuns em campos de políticas similares. Contudo, se os “domínios de políticas públicas” forem caracterizados por estruturas organizacionais mais fechadas, pode ocorrer a fragmentação e a prevalência de iniciativas isoladas (MARTINS, 2005).

Uma forma de responder a essa questão é construir alguma aquiescência interorganizacional em torno de objetivos comuns e simples, pois sua multiplicidade e ubiquidade reduzem as possibilidades de interação dos atores (O’TOOLE JUNIOR, 1993). Mas ainda podem existir desacordos entre os atores sobre as intenções de uma política ou sobre o quão apropriado é identificar, induzir e construir arranjos cooperativos. Por isso, segundo O’Toole Junior (2010), as linguagens especializadas e as rotinas diferenciadas tornam a implementação interorganizacional desafiadora ao requererem acordos que buscam ampliar a coerência entre as políticas. Em linha com esse argumento, ao analisarem a experiência canadense, Bakvis e Juillet (2004) destacam a ação dos órgãos centrais que propõem esquemas gerais de referência ("mapas conceituais”) para as áreas envolvidas em um domínio de políticas públicas; por exemplo, estratégias gerais de governo podem ser um input para induzir a cooperação e políticas mais integradas.

Contudo, a mobilização política para estimular a adesão combinada de burocracias em torno de uma agenda comum no interior dos governos pode ser custosa, demorada e incerta. Como o jogo da política interorganizacional envolve interesses diversos, os tempos de produção de acordo e a heterogeneidade de demandas podem resultar em construção de alianças internas desiguais em termos de participação e satisfação. Assim, a construção de estímulos talvez requeira a montagem de complexas operações que envolvem mais de um tipo de recurso político, a depender do perfil e demandas de cada ator.

Segundo O’Toole Junior (2010), estimular a cooperação pode minimizar a tendência à ação unilateral que inibe a “complexidade da ação conjunta” dos atores 
organizacionais, para o que se deve conhecer e identificar como agem nos domínios de políticas. Igualmente, importa analisar como compreendem o que Olsen (2008) chama de a "lógica do adequado" (logic of apropriateness): as instituições possuem um ethos sobre o que julgam ajustado para sua atuação, e que se ampara na forma como, historicamente, constituíram-se suas políticas. As regras organizacionais geram identidades que operam como mecanismos que condicionam o comportamento dos atores burocráticos. Como essa “cultura organizacional” toma tais crenças como dadas (taken for granted), “[...] instituições podem ser pervertidas por atores auto-interessados embora, para detentores de cargos atuando em favor do público, a busca de auto-interesse e simpatias pessoais seja um uso ilegítimo do cargo público.” (OLSEN, 2008, p. 30; OLSEN, 2005). Isso depõe contra a construção da “coordenação positiva” (PETERS, 1998), “cenários interorganizacionais” (O’TOOLE JUNIOR, 2010) ou “sinergia” (POLLIT, 2003; LOWNDES; SKELCHER, 1998; STEAD, 2006). Por oposição, a disponibilidade dos atores em definirem uma agenda compartilhada reduziria esses conflitos e redundâncias (PETERS, 1998) ou as tensões e contradições (POLLIT, 1998).

Contudo, a constituição de políticas públicas pode gerar arenas de poder organizacional com dificuldades de cooperação mútua. Ainda que sejam buscadas formas de coordenação para ampliar resultados coletivos, individualmente, os órgãos podem priorizar seus interesses particulares. Segundo Olson (1999, p. 77), grupos grandes, como são as burocracias governamentais, não se organizarão para uma ação coordenada ainda que em termos racionais tenham razões para tal (por exemplo, evitar redundância supondo que isso gera resultados subótimos em termos da ação coletiva de governo). As organizações, portanto, podem eleger seus objetivos e persegui-los por meios que julgam adequados às suas finalidades, ainda que ineficientes de um ponto de vista lógico.

Nesse sentido, o governo também deve avaliar os riscos e custos envolvidos para a obtenção de níveis mais elevados de integração, cujo esforço pode não gerar melhores resultados em face das clivagens de interesses políticos e organizacionais. Portanto, não é paradoxal, como afirmam Stead (2006) e Peters (1998), que o tema não seja prioridade para os atores governamentais. Isso porque, no jogo da política intragovernamental, o cálculo político dos atores pode indicar poucos benefícios de processos cooperativos que reduzam sua autonomia e demandem dividir recursos. Diante da "ameaça da autonomia”, as organizações podem responder buscando maximizar sua independência. Se as estruturas de coordenação restringem iniciativas, pode ser que as organizações sejam refratárias a participar, mesmo à custa de redundância e 
sobreposições de políticas. E isso amplia a probabilidade de fragmentação com a “[...] existência de domínios institucionais preponderantemente autônomos na execução das atividades.” (MARTINS, 2003, p. 10).

Uma estratégia de redução de conflitos seria identificar as "vantagens comparativas” de cada organização e estabelecer uma divisão de trabalho que estimule a especialização de cada órgão (POLLIT, 2003; LOWNDES; SKELCHER, 1998). Para O’Toole Junior (2010, p. 37), esse processo pode estimular uma "estrutura da interdependência” entre as organizações, e tal "cola” interorganizacional sustentaria um processo de troca social e política "[...] com suficiente capacidade de indução para consolidar a cooperação.” Mas, segundo Stead (2006), a integração é menos provável em ambientes em que os órgãos atuam mais isolados. Esses comportamentos podem se originar de culturas organizacionais pouco afetas a processos de interação e que, segundo Echebarria (2001), desincentivam a cooperação e fomentam subculturas exclusivas. ${ }^{2}$ Por tal razão, para Peters (1998, p. 304), a política interorganizacional deve considerar a natureza das questões em jogo, já que a coordenação é menos provável quando as organizações atuam em campos similares, mas se ressentem de ideias comuns. $\mathrm{O}$ autor chama isso de turf-fighting (disputa do espaço), pois as organizações se posicionam para ampliarem prerrogativas nas arenas de políticas. As organizações "solidificam” posições sobre a importância de seus serviços em vez de buscarem mecanismos mais cooperativos. Estes são os “problemas maus”, segundo O’Toole Junior (2010), pois sua natureza jurisdicional complexa requer gestão interdepartamental.

Mas como recorda Olsen (2008, p. 18), a burocracia é estimulada pela expansão quantitativa e qualitativa de suas tarefas, tema que remete à relação entre política e administração, pois objetivos políticos vagos dos líderes eleitos podem estimular a redundância de formas organizativas, por exemplo. E, do ponto de vista da democracia, tais duplicidades de atribuições entre as burocracias públicas são um desafio não apenas para a liderança política, mas também de accountability. A diluição de atividades pode ser uma consequência da redundância organizacional, e o jogo interburocrático pode criar mecanismos de proteção que se oponham a uma responsabilização social e política mais efetiva. Ou, como lembram March, Olson e Olsen (1983, p. 288) ao analisarem as reformas administrativas do governo americano:

[...] um padrão comum é que os serviços (offices) são criados inicialmente por um chefe de departamento, mais tarde adquirem um reconhecimento estatutório implícito por meio de uma lei ou audiência e apenas mais tarde são formalmente reconhecidos em legislações substantivas. Em termos de seus efeitos sobre os cus- 
tos administrativos, tamanho de staff, produtividade ou despesas, muito dos maiores esforços organizacionais têm sido descritos por leigos, e frequentemente por participantes, como falhas substanciais. Poucos ganhos em eficiência são alcançados, pouco ganho em responsividade é registrado e o controle é tão ilusório após os esforços quanto era antes.

Esses autores chamam a atenção para a accountability ex ante (verificar atividades que são criadas sem considerações mais amplas sobre sua conveniência ou mesmo redundância com outras, pois lideranças organizacionais decidem isso). Da mesma forma, para a accountability ex post (se os efeitos são vistos como falhas substanciais que reduzem a eficiência, uma das traduções possíveis é que controles fracos geram baixa responsabilização, o que pode manter o incentivo negativo às duplicidades de ações).

Nesse sentido, Stead (2006) enfatiza que a produção intersetorial de políticas deve se apoiar em arranjos interdepartamentais como comissões e grupos de trabalho para se obter o que chama de “conectividade dos departamentos”. Conforme Miller e Broussine (2005), liderança e “boa autoridade” na gestão pública pode ser uma resultante advinda também de arranjos de maior intersetorialidade entre diferentes organizações. Ou, conforme a experiência canadense relatada por Hopkins, Couture e Moore (2003), trata-se de buscar desenvolver “[...] estruturas compartilhadas orientadas por interesses comuns.” Mas se as organizações envolvidas em um campo de políticas não definem os termos da barganha e da negociação para cooperarem, a tarefa de um órgão central pode ser pouco efetiva (PETERS, 1998, p. 307). Essa questão remete ao tema das burocracias e sua ação como atores na política interorganizacional, como discute-se a seguir.

\section{A AÇÃO DAS BUROCRACIAS COMO ATORES POLÍTICOS}

Para Peters (1998), a integração governamental, ao orientar-se por prioridades, deve enfrentar o desafio da cooperação e coordenação entre as estruturas internas verticalizadas. Esses mecanismos de direção estratégica e de controle reforçam o papel político e gerencial do governo. A governance, nesse caso, refere-se à capacidade de comando, coordenação de interesses e de implementação de políticas para enfrentar o “[...] déficit na capacidade de implementação.” Ou seja, “[...] a eficiência não se esgota na agilidade da tomada de decisões, mas requer [...] capacidade de aquiescência aos comandos estatais de [...] fazer valer as decisões governamentais.” Nesse 
sentido, Diniz (2008) critica o que chama de racionalidade burocrática, que visa neutralizar a política ao reforçar a autonomia decisória das elites burocráticas. Segundo a autora, burocracia racional-legal e padrão gerencial são categorias distintas, referidas a estatutos teóricos diversos, a primeira expressando certa modalidade de relações de dominação, e a segunda representando um estilo específico de gestão.

Barzelay (1997) enfatiza que o gerenciamento governamental deveria se ajustar às orientações da política. Contudo, acaba ocorrendo uma reacomodação entre o domínio da política e as jurisdições organizacionais como consequência da definição da agenda governamental e sua implantação com a participação da gerência pública. Essa interação gera um rearranjo dos domínios internos das políticas setoriais e de suas demandas, que influencia a distribuição da autoridade organizacional sobre as decisões. Logo, as decisões sobre políticas públicas resultam da interação entre os tomadores de decisão em ambientes de expressiva atividade política e as alternativas gerenciais disponíveis. Na mesma linha, Barzelay (2004) chamará de institucionalismo processual essa abordagem que visa compreender as formas que podem assumir o relacionamento entre a política e as burocracias no interior dos governos. O institucionalismo processual desenvolve, segundo o autor, uma concepção mais abrangente sobre as mudanças no gerenciamento de governo. Em tese, novas regras organizacionais podem ser concebidas para gerar equilíbrios mais estáveis entre o subsistema político, a agenda do governo e as escolhas na construção de políticas públicas entre os top-levels executives e outros níveis hierárquicos. Decerto que a questão de algum nível de indução e estímulo institucional deve estar presente nesse jogo, sem o que a barganha conflitiva pode ser o resultado dessa dinâmica intragovernamental.

Portanto, as burocracias podem ser compreendidas como atores coletivos que mobilizam recursos para agir além das suas instituições de origem, pois a interface com outras organizações estatais é um componente importante na dinâmica interorganizacional. E como são atores organizacionais que podem moldar interesses coletivos, as burocracias podem realizar escolhas sobre a permeabilidade que admitem ou não no interior do aparato administrativo estatal. Tais preferências podem implicar distintos relacionamentos e arranjos cooperativos entre as organizações. Coordenação ou concorrência são duas das possibilidades colocadas para a ação das burocracias e seus vínculos interorganizacionais. Por tal razão, conforme Echebarria (2001, p. 13), “[...] no es indiferente para gestionar la transversalidad que la percepción mutua entre los miembros de las unidades sea de desconfianza y competencia mutua, en lugar de serlo de aceptación y cooperación.” 
Mas essa afirmação pode ser respondida de forma diferente, a depender da concepção que se adote para explicá-la. Na visão de Parsons (1956a), esse tipo de problema inexiste, pois as organizações possuem objetivos funcionalmente vinculados a demandas sociais. É o sistema social mais amplo que justifica o tipo de vínculo a ser gerado, o perfil de ajustamento buscado e, por decorrência, o nível de legitimidade das organizações. Tal abordagem vê as organizações como recurso eficiente para atender a requerimentos sociais. Como estas são meios para se atingirem fins definidos, o equilíbrio assume relevância sobre eventuais conflitos organizacionais ou interorganizacionais. O conceito-chave para a dinâmica que envolve as organizações é sua diferenciação funcional, o que supõe complementaridade ao invés de duplicação ou redundância.

Em outras palavras, equilíbrio para ofertar e receber bens e serviços não implica disputas no interior de domínios de políticas. E como as organizações são “cascas vazias” e neutras em que não há conflitos em torno de poder e dominação, sistemicamente essas características são as mesmas, o que garante maior estabilidade interorganizacional. Sendo as organizações sistemas em ação pautados por normas sociais mais amplas, os compromissos mutuamente assumidos têm esses parâmetros como referências para suas decisões, o que estimula comportamentos que favorecem a cooperação operacional entre os órgãos. E a responsabilidade com a ordem social mais ampla reforça a busca de comportamentos mais cooperativos. Como não há conflitos de natureza política, o intercâmbio entre organizações se resume a decisões alocativas de ordem técnica, visando gerar mais eficiência mútua. O resultado seria padrões integrativos generalizáveis, como contratos que regulam a relação entre as organizações e afirmam a autoridade da norma sobre os conflitos de interesses.

Portanto, as organizações não transformam os recursos que dispõem em um suporte potencial na barganha interorganizacional, mas, sim, em "poder de adaptação” a um sistema amplo de valores que evita agendas conflitantes (PARSONS, 1956b). O poder como base da cooperação, e não fonte de disputas, torna-se um meio instrumental para se alcançarem fins organizacionais e dilui a ação das burocracias como atores políticos. Assim, se o poder é visto como a capacidade de cumprir uma função, e não uma possibilidade presente nas relações políticas interorganizacionais, sua capacidade explicativa das dinâmicas institucionais se reduz. Nessa abordagem, as organizações são orientadas à convergência, o que transforma a política em um conceito abstrato e simplificado em eufemismos, como "cumprir expectativas" ou “incorporar valores”. Como na visão de Parsons (1996b), buscam-se comportamentos organizacionais previsíveis, sua tradução em decisões políticas, e sobre políticas, 
enfatiza a integração e o equilíbrio na análise institucional, suas burocracias e os vínculos que estabelecem entre si.

Muito distinta é a posição de Clegg e Lounsbury (2009) quando afirmam que a burocracia deve ser analisada como um meio racional de exercer o domínio político. Para March e Olsen (2008), os procedimentos e estruturas que definem a burocracia também defendem seus interesses, o que lhes confere o status de atores políticos. Argumentam que as instituições podem ser tratadas como atores políticos, o que reforça seu papel como tomadoras de decisão de forma autônoma. Portanto, decorre dessa afirmação que burocracias podem ser analisadas como atores autocentrados em seus interesses, em detrimento de uma racionalidade mais cooperativa em termos interinstitucionais. O grau de autonomia institucional (formal ou informal) das burocracias, portanto, pode ser uma variável independente que ajuda a explicar cenários de baixa coordenação intragovernamental.

Esse argumento também pode ser aplicado à dinâmica da política interorganizacional, considerando-se que as burocracias interagem para constituir domínios políticos e sobre políticas. E sempre que variáveis de natureza política entram em jogo, a abordagem da contingência adquire importância nas análises contextuais, pois as determinações estruturais reduzem seu poder explicativo. Daí que Clegg e Lounsbury (2009) repõem o debate sobre a burocracia menos como modelo organizativo e sua neutralidade técnica e mais como estrutura de poder e autoridade. Assim, aspectos políticos da burocracia remetem às estruturas de dominação em que conflitos e barganhas tendem a caracterizar o jogo político entre os atores organizacionais.

Aqui o “paradoxo da organização” proposto por Selznick (1943) é útil, pois as burocracias desenvolvem padrões de comportamento que buscam concentrar poder e influência na hierarquia organizacional. O importante desse argumento não é tanto a informalidade como uma consequência imprevista no modelo burocrático, mas o fato de que as burocracias agem em torno de objetivos autocentrados. Assim, no jogo político interorganizacional, os atores burocráticos podem “viciar” trajetórias institucionais para se distanciarem de processos de integração quando isso conflita com seus objetivos. Conforme Selznick (1943, p. 52), o interesse último do burocrata “[...] na organização, ou no 'bem comum', torna-se subordinado para a sua preocupação com os problemas envolvidos na manutenção de seu posto.”

Portanto, se esse raciocínio se aplica para as burocracias no interior das organizações, visando preservar e/ou ampliar seus espaços de poder, porque se imaginaria que entre os órgãos deveriam existir comportamentos mais solidários? Se, como argumenta Selznick (1984), a ação social é mediada por estruturas que geram 
novos centros de necessidades e de poder, mas também criam tensões, pode ser que compromissos mais coordenados de ação nem sempre sejam a prioridade dos atores burocráticos no interior de suas dinâmicas interorganizacionais.

Nesse sentido, a burocracia como forma de dominação pode ter uma face externa, em que é vista pela sociedade de forma impessoal, neutra e unificada, e uma face interna, caracterizada pela disputa de espaço de poder na política interorganizacional. E, paradoxalmente, pode ser que as burocracias, ao aceitarem essa dualidade, secundarizem processos cooperativos de relacionamento, pois todas podem arguir serem os representantes mais efetivos desse modelo, segundo a "lógica do apropriado". Mas, conforme Selznick (1943), a disputa entre diferentes burocracias, geralmente, ocorre sob um “pacto de silêncio”, pois transfere o debate para questões gerais. A razão desse comportamento é que as burocracias evitam expor publicamente seus argumentos, já que podem evidenciar a irrelevância da disputa interorganizacional. Mas como lembram Clegg e Lounsbury (2009, p. 127), “[...] os diferentes tipos de dominação dependem de sistemas administrativos e formas de racionalidade que estão frequentemente interligados.” Pode-se inferir que no adjetivo diferentes se abriguem atores burocráticos com distintas motivações para interagir no interior do governo, sobretudo quando os papéis que cada organização atribui a si mesma podem ser estímulos mais fortes do que a busca de interesses compartilhados.

A própria especialização do conhecimento pode contribuir para que a política interorganizacional não ocorra, embora o eufemismo das competências técnicas possa tornar menos explícito esse processo. Nesses termos, a defesa da divisão corporativa de áreas de competência pode ser apenas a superfície das disputas de poder interorganizacional. Portanto, a ordenação de crenças e as formas de ação podem impactar diferentemente as organizações e, mesmo que apresentadas racionalmente como as mais eficientes, podem servir de base para solidificar campos de atuação de reduzida interação.

Pode ser, também, que lideranças burocráticas necessitem de aliados internos para manter suas redes de poder (formais e/ou informais), o que influi na relevância que assumem objetivos organizacionais mais particularistas. Segundo Selznick (1943), as ações e políticas adotadas visam mais agir sobre as relações internas de poder do que realizar os objetivos professados. Portanto, pode ser que em uma arena interorganizacional a estrutura de poder dos órgãos seja um constrangimento para ações mais cooperativas com outras áreas.

Selnizck (1984) ainda trata dessa questão ao abordar as divisões de responsabilidade da burocracia que busca definir seus públicos-alvo alinhados às funções 
administrativas específicas. Como as estruturas burocráticas investem recursos para assumir certas incumbências, quaisquer ações percebidas como desvios dessa trajetória podem enfrentar oposição se visam alterar o status quo. Nesse sentido, a política de cooptação, que Selznick (1984) argumenta ser uma forma de envolver os grass roots na execução de programas públicos, também pode servir a outro propósito. $\mathrm{Na}$ disputa interorganizacional, o “caráter cooptativo da burocracia” pode ser um meio de institucionalizar arenas e canais que busquem reforçar vínculos entre órgãos públicos e suas contrapartes na sociedade, visando legitimar as estruturas existentes. Como destaca Olsen (2008, p. 28), o comportamento administrativo e seus resultados são influenciados, mas não determinados por regras legais, bem como as burocracias, segundo a lógica comportamental da Ciência Política, estão longe de virtuosamente seguirem normas.

Não seria diferente do exposto dizer que a institucionalização de identidades organizacionais, à la Selznick, pode tornar-se fonte de poder em si mesma. Assim, a questão das relações de dominação pode apresentar-se não apenas no interior da política organizacional, mas entre instituições. Isso porque as organizações podem invocar, para sustentar suas estruturas político-administrativas, argumentos similares de autoridade e legitimidade que operam mais como inibidores do que como estímulos de vínculos interorganizacionais. O que Clegg e Lounsbury (2009) chamam de "internalização do constrangimento” pode ser interpretado como induções a mecanismos pouco cooperativos entre organizações.

Como a lógica da burocracia enfatiza o poder disciplinador das hierarquias organizacionais, qual a razão para se supor que, voluntariamente, formas de coordenação interorganizacional fossem admitidas como superiores? O teatro do poder pode servir para analisar o jogo político entre as organizações e não apenas cada instituição em particular. E essa concepção parece alinhar-se com o argumento de que as organizações devem ser repensadas como formações discursivas e políticas em curso e locais de conflito, dominação e poder (CLEGG; LOUNSBURY, 2009).

Esses autores, ainda, chamam a atenção para as formas imperfeitas de coordenação em que regimes de poder e dominação geram fragmentação organizacional vertical e horizontal. Especialmente sobre a última, o destaque recai sobre as diferenças entre as arenas organizacionais e as razões legais, tecnológicas ou mesmo a ignorância, que impossibilitam o intercâmbio de informações. Como as burocracias buscam estabilizar seus espaços de poder, um resultado provável da política interorganizacional poderá ser certa indeterminação e algum nível de contingência que gere redundância de ações. Mecanismos imperfeitos de cooperação podem derivar da ação 
das organizações, visando preservar seus domínios de políticas. O resultado pode ser arranjos institucionais mais focados na disputa por espaços de poder do que na aproximação e que pode acentuar sua duplicação na arena interorganizacional.

Sob uma ótica um pouco distinta, Selznick (1984) descreve como dilemas legais da administração pública podem afetar a adoção de soluções organizacionais que criam novas estruturas para atuar em um mesmo campo de políticas, embora com funções separadas. ${ }^{3}$ Ambiguidades jurídicas nas competências de uma organização podem ser a causa que induza o surgimento de uma nova instituição, o que amplia os problemas de coordenação interorganizacional em face da entrada de mais atores nas arenas de políticas. Por outro lado, a trajetória das organizações pode trazer dificuldades, pois as regras e parâmetros institucionais podem ser meios que mantenham estruturas de poder dentro de limites que condicionam e constrangem a ação das burocracias, a moldura interinstitucional e os resultados daí advindos (OLSEN, 2008). Desse modo, diante da crescente complexificação das demandas das políticas públicas, a solução de criar novas organizações pode gerar o que Pierson (1993) chama de feedbacks negativos. Gera-se um processo de baixo aprendizado que pode realçar o particularismo como conduta organizacional em detrimento de mecanismos mais colaborativos e integradores de política.

É nesse sentido que Selznick (1984) destaca o “exercício da discrição”: jurisdições sobre políticas podem dificultar uma análise mais ampla do panorama de atores burocráticos que podem ser envolvidos, pois a prioridade é manter estável sua área de ação. ${ }^{4}$ Ou nos termos de Olsen (2008, p. 16), as instituições têm suas próprias dinâmicas que surgem, entre outras fontes, das tensões intra e interorganizacionais entre princípios normativos e organizacionais. O que parece ressaltar que dinâmicas centrífugas, geralmente, caracterizam a distribuição de poder entre as burocracias. Por exemplo, o insulamento burocrático, com argumentos de preservar as organizações de interferências políticas externas, pode servir de recurso político no interior das disputas interorganizacionais e reforçar comportamentos discricionários e pouco cooperativos.

Outra forma de abordar o tema é a abordagem da "administração pública gerencial”. A organização interna da administração pública deve reduzir suas linhas de comando, separar áreas centralizadas e formuladoras de políticas das unidades executoras descentralizadas e voltar-se para resultados em vez de enfatizar as normas. Para essa concepção, o burocrata neutro que aplica regras e segue de forma estrita as diretrizes definidas pelos políticos eleitos deve ser substituído pelo profissional de nível gerencial com poder discricionário para decidir sobre temas político-administrativos. Na hierarquia decisória, o dirigente público deve ser um novo ator que se coloca 
entre a liderança política e a administração burocrática para gerenciar resultados de políticas públicas (ARELLANO; CABRERO, 2005).

A delegação de autoridade para o dirigente público serve como elo de aproximação entre política e administração, contribuindo para uma nova forma de decisão no interior da gestão governamental. A nova gerência pública assume um papel político, pois as funções de formulação e implementação são exigidas para sua atuação como policy makers ao aliar conhecimento especializado com responsabilidade política. Assim, o conhecimento técnico das burocracias pode se transformar em um recurso político estratégico nas barganhas interorganizacionais, sobretudo em realidades em que o insulamento seja a regra. Em tais contextos, os sinais trocados entre a política (que descentraliza decisões) e os atores burocráticos (recebedores da delegação) podem apresentar um jogo negativo de cooperação com reflexos nos resultados da dinâmica interorganizacional dos governos.

\section{NOTAS FINAIS SOBRE A QUESTÃO DA POLÍTICA INTERORGANIZACIONAL}

Neste ensaio abordaram-se duas questões centrais: como a dinâmica da política interorganizacional pode ser analisada e de que maneira ela pode impactar a integração interna da administração pública; e como as burocracias podem atuar como atores políticos no jogo político interburocrático e, assim, afetarem a forma como as instituições governamentais atuam. Visualizou-se, ao longo deste ensaio, que ambas são questões com importância teórica e empírica para a gestão e as políticas públicas.

Em relação ao primeiro objetivo, conforme a metáfora de March, Olson e Olsen (1983), assumindo que a “política burocrática” importa, governar é menos um tema de engenharia e mais de jardinagem. Os autores querem destacar que o esforço de governar deve considerar aspectos de natureza política na relação entre as burocracias, visando alinhar atores e interesses nos domínios administrativos e institucionais. As disputas interorganizacionais, portanto, impactam a forma como se organiza a gestão interna nos governos.

Como essa questão diz respeito a temas de poder, não é somente pelo prisma de soluções técnicas apresentadas como eficientes e eficazes que ele pode ser analisado. A política interorganizacional faz parte das características da vida política dos governos e das burocracias. Portanto, o desenvolvimento institucional das organizações da administração pública também precisa ser estudado sob essa ótica. Com efeito, a 
ação dos atores burocráticos pode gerar impactos políticos, pois suas escolhas, intenções e preferências e incidem nas externalidades geradas para a sociedade.

As instituições governamentais podem ser analisadas pela lente da política interorganizacional, pois as burocracias socializam indivíduos e induzem escolhas não necessariamente compartilhadas por outros órgãos. Assim, as relações intersetoriais e entre diferentes corpos burocráticos requerem aproximar a gestão governamental de um vocabulário comum à Ciência Política, como negociação, barganhas, conflitos e convencimento. Essa é uma questão mais relevante quando atores burocráticos, visando manter e ampliar seus domínios institucionais, podem apresentar-se como respostas técnicas para não se explicitarem razões de ordem política.

A dissonância que pode ocorrer entre ação administrativa e interesses em disputa pode dificultar a construção de acordos no interior das instituições governamentais. Assim, quando uma nova política pública surge, mas preserva estruturas preexistentes que operam na mesma arena, cria-se um novo layer (estrato) que pode duplicar ações. Contudo, esta pode ser uma forma de as instituições evoluírem, pois, politicamente, seria difícil reformar ou extinguir organizações existentes (THELEN, 2003; MAHONEY; THELEN, 2010). E esse é outro resultado que pode advir da ação dos atores burocráticos no jogo político interorganizacional.

Pode ser, também, que a existência de várias soluções similares para problemas organizacionais circulem de forma simultânea entre distintas burocracias. Mas como não há condições políticas de se impor apenas uma resposta ou impedir que muitas propostas estejam em debate ao mesmo tempo, o resultado pode, igualmente, ser um conjunto de layers (níveis) que vão sendo formados e acarretam redundâncias que alimentam as disputas interorganizacionais. Mesmo o isomorfismo organizacional pode ser incapaz de lidar com os conflitos entre burocracias, pois semelhanças institucionais podem não se traduzir em uniformidade de interesses dos atores e suas condutas como atores sociais.

Organizações vistas como sistemas são difíceis de governar e/ou influenciar (KLIJN, 2008). Essa realidade pode estimular comportamentos mais ou menos cooperativos e induzir as organizações a criarem novos layers a depender de como as disputas políticas interorganizacionais ocorrem. As burocracias como atores políticos que se inserem nesse jogo podem avaliar que a convivência entre distintos interesses em questão apresente como uma opção de menor resistência conviver com redundâncias organizacionais que, ademais, dificultam ampliar conexões e intersetorialidade. Assim, em vez de mútua dependência como instrumento de evolução institucional (trajetória positiva nos termos de Klijn (2008)), pode ser que as influências que uma 
organização exerça sobre a outra caminhem na direção contrária da cooperação. Antes de ampliar sua dependência, as burocracias podem intensificar a busca por mais autonomia, mesmo que isso resulte em interações subótimas do ponto de vista das vantagens mútuas que cada organização poderia obter na sua interação com a outra. E esse é um efeito da política interorganizacional que pode ter as burocracias públicas como seus principais protagonistas.

A política interorganizacional, portanto, pode ser um processo que amplie as incertezas para se tratar da complexidade de arranjos institucionais no interior da administração pública. Colocado em outros termos, a política interorganizacional pode influir para que as organizações tenham mais dificuldades de reduzir a complexidade gerencial e administrativa, pois redundâncias, conflitos e disputas entre órgãos e suas burocracias podem criar obstáculos para se alcançarem esses objetivos. E essa pode ser uma estratégia comum nas burocracias públicas, mesmo que sejam embalagens em argumentos de viés técnico, mas que possuem conteúdos políticos visando preservar posições institucionais na política interorganizacional. Portanto, o jogo da implementação de políticas, já complexo pela presença de muitos atores organizacionais, pode ampliar suas exigências de coordenação.

Por outro lado, tanto a lógica do desacoplamento e do reacoplamento entre os mitos e cerimônias formais das instituições quanto a sua "vida real” podem estimular a política interorganizacional (HALLET, 2010; MEYER; ROWAN, 1977). Em primeiro lugar, nexos frouxos entre valores amplos e o funcionamento das organizações podem deixar brechas e espaços que permitam às instituições manterem suas atividades, ainda que sejam redundantes. Se os valores legitimadores das organizações estão na sociedade, o desacoplamento pode estimular que mais de uma instituição reivindique ser a porta-voz que traduza formalmente tais questões. E se nesse processo mais de uma organização assume a "representação" de valores sociais, pode-se gerar uma "dependência da trajetória” que torne mais difícil evitar futuras disputas entre elas. Um domínio de políticas pode moldar um ambiente em que, segundo Meyer e Rowan (1977, p. 348), “[...] poderosas organizações forçam suas imediatas redes de relacionamento para se adaptarem às suas estruturas e relações.” Se burocracias públicas fazem deste um insumo no interior das disputas interorganizacionais, os denominadores comuns em termos de racionalidade administrativa tendem a ser pouco relevantes e se distanciar da busca das "políticas de coordenação horizontal”, como Peters (1998) propõe.

O contrário também pode realçar a política interorganizacional, pois o reacoplamento que aproxime os gaps entre valores sociais mais amplos e o funcionamento 
das organizações pode reforçar identidades particularistas em nome da "lógica do adequado”. Para Meyer e Rowan (1977, p. 349), quando uma organização adere às prescrições de mitos (ou valores) em um ambiente institucional, ela:

[...] demonstra que está atuando sobre valiosos propósitos coletivos e de uma maneira adequada. [...] A incorporação de elementos institucionalizados fornece uma explicação [...] de suas atividades que a protege de ter sua conduta questionada. A organização torna-se, em uma palavra, legítima e usa sua legitimidade para reforçar seu apoio e assegurar sua sobrevivência.

Mas tanto o desacoplamento quanto o reacoplamento podem se transformar em mecanismos que reforcem práticas de insulamento que reduzam a transparência no interior do jogo político interorganizacional. Ambas as situações podem reduzir a accountability mútua entre organizações que atuam na mesma arena de políticas e estimular práticas em busca de autonomia, visando reforçar posições no interior da política interorganizacional. Como lembra Hallet (2010), a vida organizacional pode ser vista como um “terreno contestado” em torno de pressões institucionais concorrentes e conflitos de interesse. Se assim é, nada autoriza a conclusão de que a política interorganizacional seria mais virtuosa e orientada por cooperação e não por disputas. Portanto, investigar o jogo de poder interorganizacional pode ser uma pista importante para se analisar como organizações se adaptam às situações com as quais se deparam e como, desse modo, influenciam o contexto social e político no qual se inserem (BARLEY, 2010) de modo mais coordenado ou por interesses mais particularistas dos atores burocráticos.

É nessa linha que, conforme Cunill Grau (2005), o debate sobre a gestão interorganizacional e a busca de integração entre setores e políticas públicas é um tema com um claro fundamento político, pois se trata de planejar formas de se perseguirem objetivos governamentais em bases mais cooperativas em torno dos recursos manejados pelos diversos setores. Por suposto, dividir conhecimentos, tecnologias e capacidades estatais está longe de ser apenas um tema de cunho administrativo. A forma como atores burocráticos manejam esses recursos influi e é condicionada pela política interorganizacional que, a depender do jogo de poder e dos interesses em jogo, pode deixar em segundo plano as vantagens técnicas da cooperação intersetorial. E como essa é uma questão contingente de diferentes contextos institucionais, o tema aqui discutido, ademais de sua relevância teórica, demanda análises empíricas para descortinar como esse processo ocorre no interior da gestão pública. 
Notas explicativas:

${ }^{1}$ Segundo o autor, lacuna ocorre quando nenhuma organização executa uma tarefa; incoerência manifesta-se se quando um mesmo grupo social tem objetivos diferentes; e, redundância decorre de duas ou mais instituições executarem a mesma atividade. Será sobre essa última que recairá a análise de caso neste artigo. Por outro lado, como Peters (1998) apresenta as três modalidades de "problemas de coordenação" de forma estática, não explora as possibilidades analíticas de vínculos entre elas. Assim, a lacuna de ação pública em um setor, comum em políticas que requerem decisões sobre temas controversos, pode, à medida que muda o "humor geral”, ser sucedida por um ativismo estatal que gera redundância de iniciativas. Estas, com o passar do tempo, podem se tornar incoerentes, pois ao redor de cada política se constituem redes de interesse e clientelas específicas.

${ }^{2}$ Essa parece ter sido a trilha seguida pelo institucionalismo organizacional após Selznick (1984) frisar que as instituições geram valores e identidades coletivos que se transformam em fins para si mesmos. ${ }^{3}$ Selznick (1984) se refere ao fato de a Tenesse Valey Authority (TVA) operar no apoio técnico de programas de desenvolvimento regional, mas estar legalmente proibida de manejar os recursos financeiros das cooperativas de agricultores. A solução adotada foi criar a Tenesse Valey Associative Cooperative (TVAC) para administrar essas subvenções financeiras.

${ }^{4}$ Tal situação se exemplifica na dificuldade de a TVA analisar a participação de instituições negras como grass roots e as relações que foram criadas com a American Farm Bureau Federation.

\section{REFERÊNCIAS}

ARELLANO, D.; CABRERO, E. La nueva gestión pública e su teoria de la organización: son argumentos antiliberales? Justicia y equidad en el debate organizacional público. Gestión y Política Pública, Ciudad de México, v. 14, n. 3, p. 599-618, jul./ dic. 2005.

ARIZNABARRETA, K. E. Capital social, cultura organizativa y transversalidad en la gestión pública. In: CONGRESO INTERNACIONAL DEL CLAD SOBRE LA REFORMA DEL ESTADO Y LA ADMINISTRACIÓN PÚBLICA, 6., 2001. Buenos Aires. Anais... Buenos Aires: República Argentina, 2001. 1 CD-ROM.

BACARACH, P.; BARATZ, M. S. Two faces of power. The American Political Science Review, Los Angeles, v. 56, i. 4, p. 947-952, Dec. 1962.

BAKVIS, H.; JUILLET, L. O desafio horizontal: ministérios setoriais, órgãos centrais e liderança. Cadernos ENAP, Brasília, DF: ENAP, n. 27, 2004.

BARDIN, L. Análise de conteúdo. Lisboa: Edições 70, 2008. 
BARLEY, S. R. Building an institutional field to corral a government: a case to set an agenda for organization studies. Organization Studies, v. 31, p. 777-805, Oct. 2004.

BARZELAY, M. From “New Institutionalism” to “Institutional Processualism”: Advancing Knowledge about Public Management Policy Change. In: CONFERENCE ON THIRD GENERATION REFORM IN BRAZIL AND OTHER NATIONS, 2004, Rio de Janeiro. Anais... Rio de Janeiro, 2004. 1 CD-ROM.

BARZELAY, M. La reforma de la Administración Pública: un enfoque de Políticas (con referencia a los países de la OCDE). In: CONGRESO INTERNACIONAL DEL CLAD SOBRE LA REFORMA DEL ESTADO Y DE LA ADMINISTRACIÓN PÚBLICA ISLA MARGARITA, 2., 1997, Venezuela. Anais... Venezuela, out. 1997. Disponível em: <https://bvc.cgu.gov.br/bitstream/123456789/2766/1/reforma_administracion_publica_enfoque.pdf >. Acesso em: 20 jun. 2008.

BOGASON, P. Changes in the Scandinavian model: from bureaucratic command to interorganizational negotiation. Public Administration, v. 76, p. 335-354, Summer 1998.

BROUSSINE, M.; MILLER, C. Leadership, ethical dilemmas and "good” authority in public service partnership working. Journal compilation, p. 379-391, 2005.

CLEGG, S.; LOUNSBURY, M. Weber: Sintering the Iron Cage. In: ADLEER, P. S. (Ed.). The Oxford Handbook of Sociology and Organization Studies: Classical Foundations. Oxford: Oxford Handbooks, 2009. cap 6, p. 118-173.

COHEN, M. D.; MARCH J. G.; OLSEN, J. P. A garbage can model of organizational choice. Administrative Science Quarterly, v. 17, p. 1-25, Mar. 1972.

CUNILL GRAU, N. La intersectorialidad en el gobierno y gestión de la política social. Trabajo elaborado por encargo del Diálogo Regional de Política del Banco Interamericano de Desarrollo. 2005.

DAHL, R. A. Who Governs? Democracy and Power in an American City. New Haven, London: Yale University Press, 1989.

DINIZ, E. Reforma do Estado e Governança Democrática: em direção à democracia sustentada? In: CONFERENCIA DEMOCRACIA, GOBERNANZA Y BIENESTAR EN LAS SOCIEDADES GLOBALES, 2008, Barcelona. Anais... Barcelona: Instituto Internacional de Gobernabilidad de Catalunya, 2008. Disponível em: <http://www. ie.ufrj.br/aparte/pdfs/elidiniz_reforma_do_estado.pdf>. Acesso em: 25 abr. 2009. 
GIL, A. C. Métodos e técnicas de pesquisa social. São Paulo: Atlas, 2010.

HOPKINS, M.; COUTURE, C.; MOORE, E. Do heróico ao cotidiano: lições aprendidas na condução de projetos horizontais. Cadernos ENAP, Brasília, DF: ENAP, v. 24, 2003.

JAMIL, I. La cultura administrativa: una forma de comprender la administración pública en distintas culturas. Gestión y Política Pública, Ciudad de México, v. 8, n. 1, p. 61-82, enero/jun. 1998.

KLIJN, E.-H. Administration: What's new? Key concepts in complexity theory compared to their counterparts in public administration research. Public Management Review, v. 10, i. 3, p. 299-317, May 2008.

KNOPF, J. W. Doing a Literature Review. OS: Political Science \& Politics, i. 1, p. 127-132, Jan. 2006. Disponível em: <http://journals.cambridge.org/action/displayAbstract ? fromPage $=$ online $\&$ aid $=386229 \&$ fileId $=S 1049096506060264>$. Acesso em: 20 maio 2013.

LINDBLOM, C. E. O processo de decisão política. Brasília, DF: Ed. Universidade de Brasília, 1980.

LINDBLOM, C. E. The science of muddling through. Public Administration Review, v. 19, p. 79-88, Spring 1959.

LOWI, T. J. American Business, Public Policy, Case Studies, and Political Theory. World Politics, Baltimore, v. 16, i. 4, p. 677-715, July 1964.

LOWNDES, V.; SKELCHER, C. The dynamics of multi-organizational partnerships: an analysis of changing modes of governance. Public Administration, v. 76, p. 313-333, Summer 1998.

MAHONEY, J.; THELEN, K. A theory of gradual institutional change. In: MAHONEY, J.; THELEN, K. (Ed.). Explaining institutional change: ambiguity, agency, and power. Cambridge: Cambridge University Press, 2010. cap. 1, p. 1-37.

MARCH, J. G.; OLSEN, J. P. Neo-institucionalismo: fatores organizacionais na vida política. Revista de Sociologia e Política, v. 16, n. 31, p. 121-142, nov. 2008. 
MARCH, J. G.; OLSON, J. P.; OLSEN, J. P. Organizing political life: what administrative reorganization tells us about government. The American Political Science Review, v. 77, i. 2, p. 281-296, June 1983.

MARTINS, H. F. Fragmentação e intersetorialidade: em busca de uma agenda de integração. Gestão pública no Brasil contemporâneo. Programa avançado em gestão pública contemporânea. São Paulo: FUNDAP: Casa Civil, 2005.

MCMENAMIN, I. Process and text: teaching students to review the literature. Political Science \& Politics, i. 2, p. 133-135, Jan. 2006. Disponível em: <http:// journals.cambridge.org/action/displayAbstract?fromPage $=$ online $\&$ aid $=386241 \&$ fileId=S1049096506060306 > . Acesso em: 20 maio 2013.

MEYER, J. W.; ROWAN, B. Institutionalized organizations: formal structure as myth and cerimony. The American Journal of Sociology, v. 83, i. 2, p. 340-363, Sept. 1977.

MINTZBERG, H. Administrando governos, governando administradores. Revista do Serviço Público, Brasília, DF: ENAP, v. 49, n. 4, p. 148-163, out./dez. 1998.

OLSEN, J. P. Maybe it is time to rediscover bureaucracy. Journal of Public Administration Research and Theory, v. 16, i. 1, p. 1-24, Mar. 2005. Disponível em: <doi:10.1093/jopart/mui027>. Acesso em: 20 maio 2013.

OLSEN, J. P. The ups and downs of bureaucratic organization. Annual Review of Political Science, v. 11, p. 13-37, Jan. 2008.

OLSON, M. A lógica da ação coletiva: os benefícios públicos e uma teoria dos grupos sociais. São Paulo: Edusp, 1999.

O’TOOLE JUNIOR, L. J. Interorganizational policy studies: lessons drawn from implementation research. Journal of Public Administration Research and Theory, v. 3, i. 2, p. 232-251, Apr. 1993.

O’TOOLE JUNIOR, L. J. Managing horizontal government: the politics of co-ordination. Public Administration, v. 76, p. 295-311, Summer 1998.

O’TOOLE JUNIOR, L. J. Relações interorganizacionais no processo de implementação. In: PETERS, B. G.; PIERRE, J. (Org.). Administração pública: coletânea. Brasília, DF: Ed. Unesp, 2010. p. 229-249. 
PARSONS, T. Suggestions for a sociological approach to the theory of organizations-I. Administrative Science Quarterly, v. 1, i. 1, p. 63-85, June 1956a.

PARSONS, T. Suggestions for a sociological approach to the theory of organizations-II. Administrative Science Quarterly, v. 1, i. 2, p. 225-239, Sept. 1956b.

PETERS, B. G. La capacidad para gobernar: retrociedendo hacia al centro? Revista Reforma y Democracia, Caracas, v. 27, p. 7-21, oct. 2003.

PETERS, B. G. Managing horizontal government: the politics of coordination. Public Administration, v. 76, p. 295-311, June 1998.

PIERSON, P. When the effect becomes cause: policy feedback and political change. World Politics, v. 45, p. 595-628, July 1993.

POLLIT, C. Joined-up government: a survey. Political Studies Review, v. 1, p. 3449, Feb. 2003.

SELZNICK, P. An approach to a theory of bureaucracy. American Sociology Review, v. 8, i. 1, p. 47-54, Feb. 1943.

SELZNICK, P. TVA and the grass roots: a study of politics and organization. Berkeley: Los Angeles, London: University of California Press, 1984.

STEAD, D. Institutional barriers to policy integration: what they are and how they might be overcome. In: ANNUAL CONFERENCE PUBLIC MANAGERS UNDER PRESSURE: BETWEEN POLITICS, PROFESSIONALISM AND CIVIL SOCIETY, 2006, Milão. Anais... Milão, 2006. p. 1-12.

THELEN, K. How institutions evolve: insights from comparative historical analysis. In: MAHONEY, J.; RUESCHEMEYER, D. (Ed.). Comparative Historical Analysis in the Social Sciences. Cambridge: Cambridge University Press, 2003. cap. 6, p. 208-225. 
Como citar este artigo:

\begin{abstract}
ABNT
GRIN, Eduardo, José. Atores burocráticos e sua atuação política no interior da gestão governamental. RACE, Revista de Administração, Contabilidade e Economia, Joaçaba: Ed. Unoesc, v. 15, n. 2, p. 475-504, maio/ago. 2016. Disponível em: $<$ http://editora.unoesc.edu.br/index.php/race>. Acesso em: dia/mês/ano.
\end{abstract}

\title{
APA
}

Grin, E. J. (2016). Atores burocráticos e sua atuação política no interior da gestão governamental . RACE, Revista de Administração, Contabilidade e Economia, 15(2), 475-504. Recuperado, de http://editora.unoesc.edu.br/index.php/race 